\title{
Pesquisa em Design com crianças: caminhos possíveis
}

\author{
Camila Andrade dos Santos ${ }^{1}$; \\ Márcio James Soares Guimarães²;
}

\section{resumo:}

0 artigo apresenta uma reflexão em torno de aspectos inerentes à pesquisa em Design com crianças, a partir de duas experiências de pesquisa desenvolvidas pelos autores, e baseada em 6 condições: 0 perfil das crianças; o tempo de pesquisa; o espaço de pesquisa; a metodologia; recursos e dispositivos; ética e compromisso. $\mathrm{O}$ objetivo é apontar caminhos possíveis à realização de estudos na área envolvendo o público infantil. Como resultado, estabelece diálogo com investigadores e apresenta viabilidade de recursos e métodos de pesquisa em Design para as infâncias, tocando também em questões de inclusão.

palavras-chave:

infâncias; inclusão; participação infantil; métodos de pesquisa com crianças na área do Design.

Espaço reservado para organização do congresso.

\footnotetext{
${ }^{1}$ http://lattes.cnpq.br/7768340690883764

2 http://lattes.cnpq.br/9511208974215435
} 


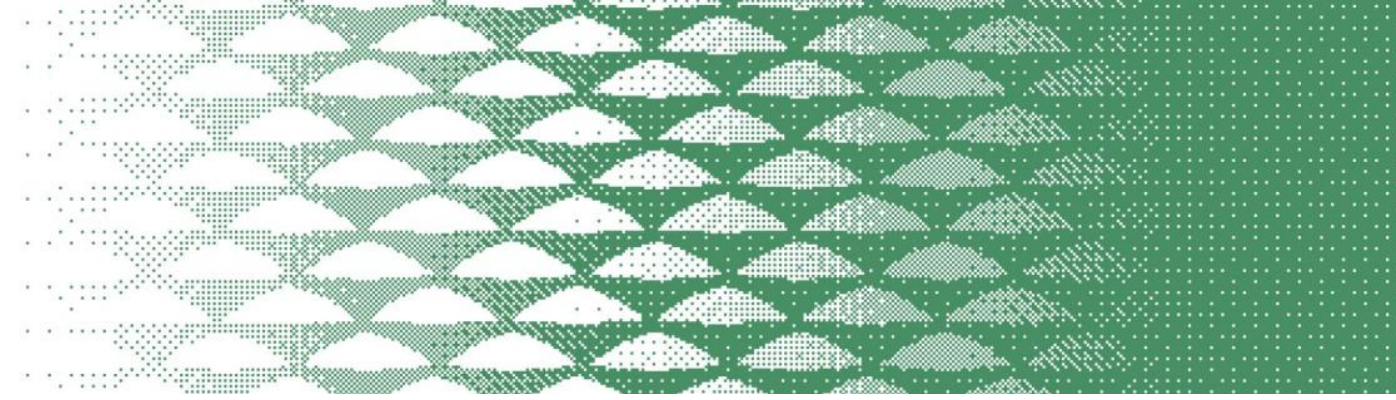

Ainda segundo a mesma autora, "ao contrário de seres incompletos, treinando para a vida adulta, encenando papéis sociais enquanto são socializados ou adquirindo competências e formando sua personalidade social, [as crianças] passam a ter um papel ativo na definição de sua própria condição" (COHN, 2005, p. 21). Apoiando-nos na reflexão da autora, tentemos tratar das especificidades de cada infância, inseridas em seu contexto, e com direito à autodeterminação e a ser por si mesma.

A partir desse entendimento e da noção da importância dos conhecimentos trazidos pelas crianças serem levados em consideração, ratificamos a noção de que tais sujeitos não são "iguais em todo lugar", mas diferentes a partir de seus contextos, obrigando o pesquisador a levar em conta suas próprias vozes. Tal perspectiva metodológica leva, necessariamente, a atentar para as várias formas de as crianças serem, sentirem, fazerem e falarem, que devem ser respeitadas (FERNANDES \& FRANÇA, 2020).

Na mesma linha teórica, autores como Cohn e Fernandes \& França, indicam que a pesquisa em Design deve ser situada, a exemplo do que dizem Serpa et al. (2018, p. 1586):

A investigação metodológica que estrutura nossa pesquisa tem interesse em ferramentas contextuais, situadas em contextos específicos, contando com suas particularidades, questões, públicos e possíveis fatores imprevisíveis que moldam esses encontros (Olander, 2014). O processo de elaboração das dinâmicas e os encontros onde elas acontecem são espaços orgânicos que influenciam um ao outro, guiando e alimentando a pesquisa através de reflexões das pesquisadoras e do restante do coletivo (Binder et al., 2011)

Ainda sobre os aspectos inerentes à individualidade das crianças, é necessário conhecer bem o grupo etário integrante do universo empírico da pesquisa: suas habilidades, capacidades e estágios de desenvolvimento, fatores importantes para melhor orientar a prática de pesquisa e seus dispositivos.

\subsection{Tempo de pesquisa: o controle do tempo e as distinções entre adultos e crianças no processo de pesquisa}

Os adultos, alfabetizados e necessitados de controlar o tempo, usam os recursos disponíveis para organizar suas tarefas cotidianas. Sem pode contar as horas, os minutos ou controlar os dias da semana, os meses, anos, viver em nossa sociedade se tornaria uma tarefa difícil. Embora os adultos frequentemente venham tentando enquadrar as crianças em sua contagem de tempo, estas pequenas pessoas têm suas próprias noções de temporalidade. Sendo assim, estabelecer períodos de execução de tarefas no cronograma da pesquisa, para que sejam cumpridas milimetricamente por elas, é um desafio quiçá impossível de alcançar. Toda pesquisa é orientada por uma distribuição temporal de etapas e atividades, mas conseguiremos nós, pesquisadores, impor esse cronograma aos nossos sujeitos crianças? Não que as crianças sejam incapazes de firmar compromissos, mas o tempo para desenvolver suas atividades não é contado de forma racional como o dos adultos. Desta forma, alterações no cronograma, baseadas na disponibilidade das crianças e necessidade de adequações, são passíveis de ocorrer. Sendo assim, contar com o auxílio dos responsáveis (sejam pais ou professores) e o acompanhamento mais próximo desses sujeitos pode ser uma boa estratégia para conseguir melhores resultados.

Em todo processo de pesquisa os sujeitos podem desistir a qualquer momento da interlocução com o pesquisador e este fato é algo a ser considerado desde o princípio, prevendo alterações no número de pesquisados, o que poderá influenciar também a qualidade das informações obtidas. Um número pretendido de pesquisados pode ser reduzido significativamente no decorrer da pesquisa, levando o pesquisador a estabelecer uma margem de absenteísmo e formas de supri-la. 


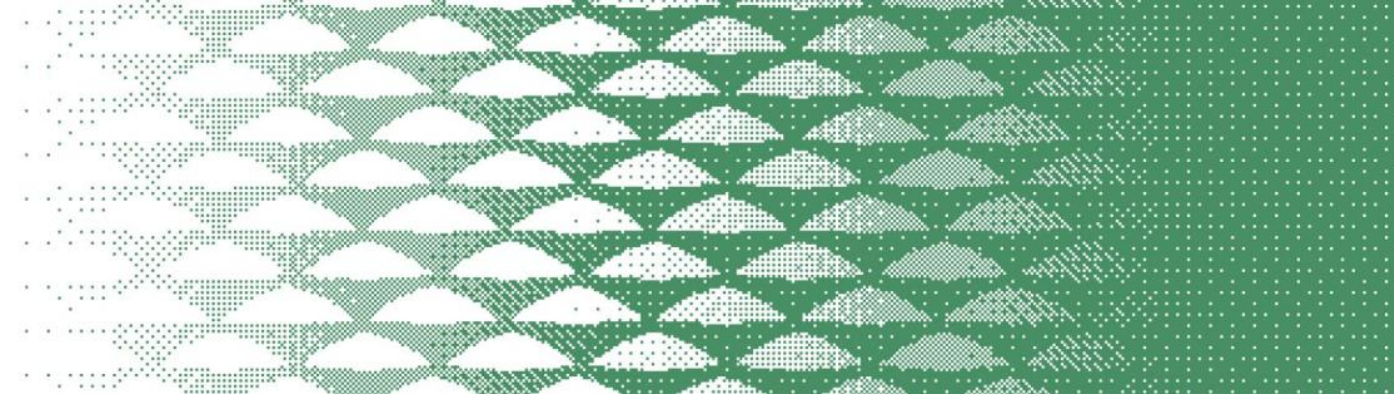

\subsection{O Espaço de pesquisa: locus possíveis}

A pesquisa com o envolvimento de seres humanos em suas relações da vida em sociedade, tanto no caso das ciências sociais, como na perspectiva do Design aqui proposta, implica na escolha de um universo empírico. As características do espaço de pesquisa são um fator fundamental para o bom andamento da ação. Pesquisar com crianças significa negociar com adultos, os pais ou responsáveis, principalmente. Mediações entre o pesquisador e a criança podem se fazer necessárias e, portanto, escolher uma entidade que já desenvolve projeto com crianças ou reúne este público, pode facilitar o processo. Neste sentido, a escola é um local propício para se tramitar os consentimentos necessários a execução da pesquisa, tais como termos de consentimento e de assentimento, direcionados, respectivamente, aos responsáveis e às crianças. Estabelecer parcerias com escolas trará segurança para o pesquisador, para os pesquisados e para seus responsáveis, mas certamente existirão outras possibilidades, a depender do universo empírico: associações, igrejas e outros agrupamentos existentes.

\subsection{A metodologia: abordagens, recursos e dispositivos}

Para além de consultar as crianças sobre os projetos a elas destinados, deve-se abrir um espaço de participação em que o pesquisador recorre a elas em todo processo, para ouvi-las. Para além de serem convidadas a testar soluções de Design, os sujeitos da pesquisa podem e devem participar de todo o processo de desenvolvimento de propostas para seu uso, aumentando as chances de que o artefato desenvolvido faça mais sentido para elas. Isto é alcançado a partir de métodos, técnicas e ferramentas cujos processos favoreçam uma melhor interação entre quem projeta e aqueles a quem os projetos se destinam. Essa participação ativa das crianças ao longo dos processos de pesquisa em Design, possibilita uma co-construção de requisitos e, consequentemente, de resultados com maiores chances de atenderem as expectativas desse público. Trazer esse conhecimento tácito infantil para dentro da pesquisa e considerar as múltiplas experiências de todos os agentes envolvidos no processo poderá ajudar a melhor orientar a prática do designer.

Em pesquisa com crianças as abordagens tradicionais, incluindo entrevistas e questionários em suas formas mais consagradas, talvez não deem conta da tarefa de reunir informações de uma forma eficiente e eficaz. Usar de métodos quantitativos e qualitativos puros, não adaptados ao universo, pode resultar em obtenção de repostas aparentemente objetivas, deixando de lado importantes nuances que poderiam ser transformadas em requisitos de projeto. Outras abordagens, transformando essas metodologias "clássicas", pensadas para os adultos, contribuiriam para a prática do Design e, consequentemente, para a criação de produtos que influenciem positiva e diretamente no grau de satisfação das pessoas para as quais os esforços do designer se destinam.

Para apreender os anseios e necessidades desse público há várias estratégias a serem adotadas por pesquisadores/técnicos, de modo a conseguir respostas de projeto. Essas estratégias serão eficientes, de maneira a não só colocar questões às crianças esperando respostas objetivas, mas possibilitando um olhar mais profundo, ao facilitar o acesso a informações para além do que elas conseguem verbalizar. Para dar conta desses aspectos, e buscando olhar o mundo por meio dos olhos dos sujeitos, é aconselhável adotar a observação direta e participante, tal como o fazem os etnógrafos, bem como partir das teorias do desenvolvimento infantil. Tais posturas podem proporcionar aproximações mais produtivas e mais respeitosas para com o universo infantil e sua compreensão de mundo.

A teoria disponível na área, a capacidade criativa inerente ao nosso contexto de atuação, as várias ferramentas disponíveis e a capacidade inventiva de, inclusive, adaptar essas ferramentas ao contexto 


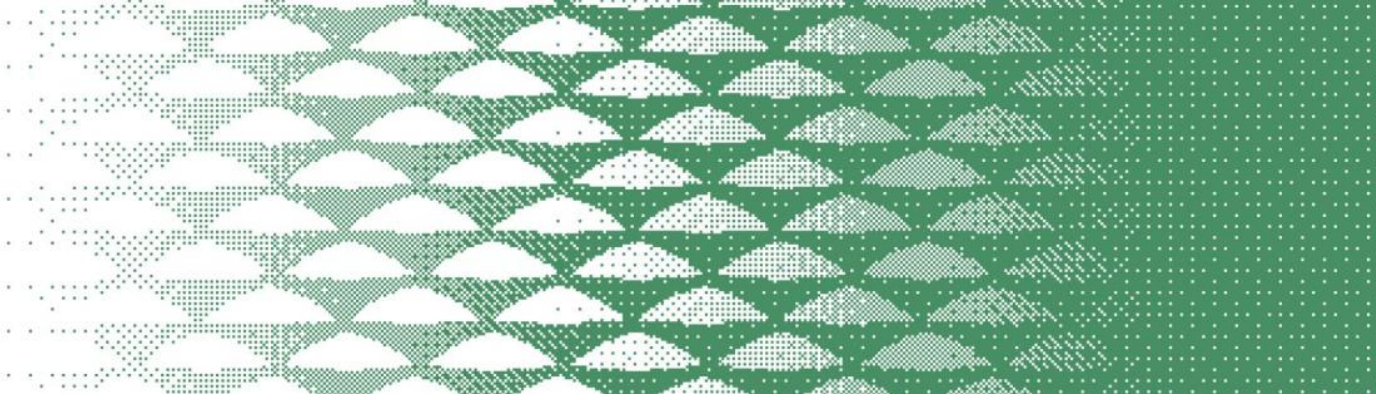

pretendido, nos coloca a nós, designers, em um lugar confortável e acessível para adaptar métodos e técnicas para além das formas de pesquisa tradicionais, geralmente usadas por pesquisadores das diversas áreas com o púbico adulto. Nesse sentido, as chances de um melhor engajamento dos sujeitos infantis na pesquisa são maiores. Deste modo, estudo com crianças na área do Design pode ser conduzido a partir de uma pesquisa familiar à área: aquela baseada na prática de projeto. "A prática do projeto envolve pesquisa assim como a prática de pesquisa envolve design” (Brandt \& Binder, 2007). Neste sentido, podem ser utilizados métodos, técnicas e ferramentas projetuais do Design como recursos de pesquisa.

Como estratégia, a investigação poderá ser precedida pela ferramenta de pesquisa preliminar - o survey -com objetivo de apreender elementos para tomada de decisão sobre quais tipos de técnicas e ferramentas adotar para responder aos objetivos de pesquisa/projeto, e sobre quais dinâmicas são passíveis de serem desenvolvidas e, ainda, definir com mais precisão o perfil dos sujeitos de pesquisa que foram estimados. O survey poderá servir, também para avaliar quais e como serão solicitadas as autorizações para a participação na pesquisa.

Não somente a adoção de abordagens mais direcionados ao universo das crianças, mas também o uso de artefatos lúdicos e didáticos com apelo visual, são importantes estratégias de pesquisa neste caso e o designer, dada a sua formação, tem condições de viabilizar tais instrumentos.

As tabelas 01 e 02 trazem alguns exemplos de processos, artifícios, tecnologias para a pesquisa com crianças e também dispositivos que fomentam a participação.

Tabela 1 - Abordagens possíveis para a pesquisa com crianças

\begin{tabular}{|l|}
\hline Abordagens \\
\hline Criação de Cenários (Halse, 2010) \\
\hline Jogos de Design (Brandt, 2010) \\
\hline Prototipagem generativa (Spinuzzi, 2005) \\
\hline Design participativo (Binder, 2011) \\
\hline Grupo focal \\
\hline Design Thinking com crianças \\
\hline Visita virtual de campo \\
\hline Photovoice \\
\hline Observação direta \\
\hline Observação participante \\
\hline Etnografia \\
\hline
\end{tabular}

Tabela 2 - Ferramentas possíveis para a pesquisa com crianças

\begin{tabular}{|l|}
\hline Ferramentas \\
\hline Fotografia e fotocolagem \\
\hline Artes plásticas \\
\hline Dança e dramatização \\
\hline Parede de ação participativa \\
\hline Mapa conceitual \\
\hline Audiovisual \\
\hline Caderno de campo das crianças \\
\hline Visita de campo guiada pelas crianças \\
\hline Brincadeiras e dinâmicas \\
\hline
\end{tabular}




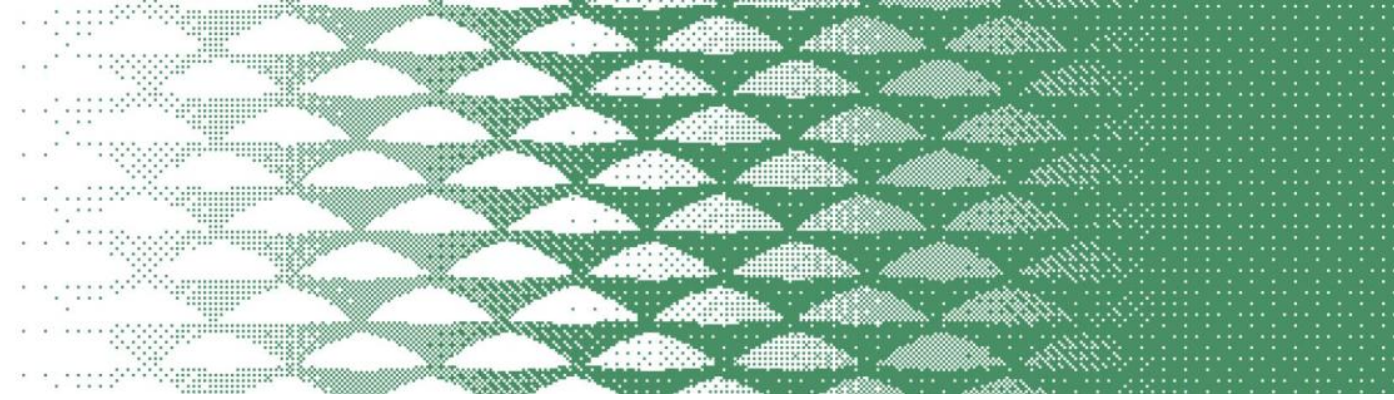

Bodystorming

Folha de atividades

\section{5 Ética e compromisso}

Por tudo o que dissemos até agora, o consentimento (e o engajamento) da criança é tão ou mais primordial do que o dos adultos nos demais processos de pesquisa. A criança deve se sentir com desejo e à vontade para participar da pesquisa. De acordo com os preceitos legais, os pais ou responsáveis devem autorizar formalmente a participação da criança e todos os acordos devem estabelecidos e documentados no início do processo.

Considerando que o Design tem a imagem muito presente em seu fazer e utiliza bem os recursos de fotografia, pensá-la na pesquisa é fundamental. Muito se têm discutido sobre como as imagens das crianças serão retratadas nos produtos da pesquisa (relatórios, dissertações, teses e artigos científicos). Fernandes e Caputo (2020) trazem uma reflexão sobre formas de pensar eticamente o uso da imagem nas pesquisas com crianças (imagens de crianças e com crianças), "de modo a respeitarmos a criança enquanto participante e autora, num profundo respeito pelos seus direitos" (FERNANDES \& CAPUTO, 2020, p. 05). Trazem, portanto, a discussão da dicotomia "imagem-fantasma da criança" e "imagens da criança-sujeito". Na primeira categoria, a "imagem-fantasma da criança", as autoras conceituam como aquelas imagens em que aparecem somente os contornos de crianças, crianças desfocadas ou fotografadas de costas. Segundo as autoras, "em grande parte destes casos tais decisões são tomadas pelos Comitês de Ética, que, sob a égide da proteção da criança, nunca permitem que os sujeitos envolvidos possam ter conhecimento e manifestar sua concordância ou não acerca da participação na pesquisa" (FERNANDES \& CAPUTO, 2020, p. 18). Sobre a segunda categoria, as autoras trazem uma opção de eliminar a "fantasmagoria imagética, desde que a criança, sendo possível decidir, decida por sua própria vontade": a "imagem da criança-sujeito", embasada nos direitos da criança e que citam a Convenção das Nações Unidas sobre os Direito da Criança. Dito isto, decidir sobre a metodologia do uso das imagens deve considerar os objetivos da pesquisa e o respeito aos direitos da criança.

Nunca é demais dizer da necessidade de sempre trazer de volta, retornar os resultados da pesquisa para a criança saber o que resultou daquilo que ela contribuiu, seja um artefato, seja um estudo. Neste sentido, bom lembrar a existência de uma resolução, do CNS 510/2016, que trata das "especificidades éticas das pesquisas nas ciências humanas e sociais e de outras que se utilizam de metodologias próprias dessas áreas". Cabe, portanto, ao pesquisador avaliar, baseado nas especificidades e objetivos de pesquisa, sobre essa especificidade à luz dos objetivos da pesquisa. Na escolha por não mostrar a imagem da criança, técnicas como o desenho podem ser utilizadas para ilustrar a ação.

\section{Conclusão}

Neste trabalho, estabelecemos alguns parâmetros para nortear a relação do designer com seus sujeitos de pesquisa quando estes são crianças - e que não se esgotam por aqui - que podem auxiliar no melhor desenvolvimento do estudo. A partir das experiências de pesquisa narradas e do que estabelecemos como pontos relevantes da pesquisa em Design com crianças, a serem considerados pelo pesquisador, concluímos que a pesquisa envolvendo este público deve ser agradável, condizente com o grupo etário, curiosa, prazerosa, interessante, desafiadora, engajadora, lúdica, educacional (crianças gostam de aprender e gostam de aprender brincando). 
Por suas características e procedimentos metodológicos próprios, o Design tem potencial para mediar de forma criativa, lúdica e envolvente tarefas e materiais de pesquisa. Para tanto, o pesquisador cujo foco de estudo é a infância deve, primordialmente, ter a vontade e o prazer de pesquisar com este público, encontrando-se motivado a ser sociável, paciente, adaptável, criativo e engajador. Em uma situação ideal, a pesquisa deve explorar, também, a contrapartida do estudo para as crianças envolvidas. Como lugar de interação e trocas de saberes em que o pesquisador aprende com elas e elas aprendem com a pesquisa, pensar de que maneira o estudo contribuirá com os sujeitos envolvidos: seja como retorno direto às próprias crianças (os artefatos que a elas se destinam); seja afetando positivamente o seu aprendizado a partir dos métodos aplicados (como o photovoice em que se aprende técnicas de fotografia); seja proporcionando seu engajamento em questões que as envolvem, a partir de métodos participativos, por exemplo, ou proporcionando seu entretenimento.

Design research with children: possible paths

Abstract: The article presents a reflection around aspects inherent to research in Design with children, based on two research experiences developed by the authors, and based on 6 conditions: the profile of children; research time; the research space; the methodology; resources and devices; ethics and commitment. The objective is to point out possible ways to carry out studies in the area involving children. As a result, it establishes a dialogue with researchers and presents viability of resources and research methods in Design for children, also touching on issues of inclusion.

Keywords: childhoods; inclusion; child participation; research methods with children in the field of Design.

\section{Referências bibliográficas}

ARIZPE, Evelyn; STYLES, Morag. Lectura de Imágenes: los niños interpretan textos visuales. México: FCE, 2004.

BRANDT, Eva. Playing design games. Rehersing the future. Copenhagen: The Danish Design School Press, 2010.

BINDER, T.; BRANDT, E., EHN, P., \& HALSE, J. (2015). Democratic design experiments between parliament and laboratory. CoDesign, 11(3-4), 152-165.

BINDER, T., DE MICHELIS, G., EHN, P., JACUGGI, G., LINDE, P.; WAGNER I. Design Things. Cambridge, MA: The MIT Press, 2011.

BRASIL. (1990) Lei no 8.069, de 13 de julho de 1990, Estatuto da Criança e do Adolescente.

COHN, Clarice. Antropologia da criança. Rio de Janeiro: Jorge Zahar Editor, 2005a. 58p.

FERNANDES, Natália.; CAPUTO, Stella Guedes. Quem tem medo das imagens das crianças na pesquisa? Contributos para a utilização de imagens na pesquisa com crianças. In: Sociedad e Infâncias. 5, 2020: 5-19.

GUIMARÃES, Márcio James Soares. Design Inclusivo na Contemporaneidade: diretrizes ao desenvolvimento de materiais didáticos acessíveis a crianças cegas e com baixa visão. Tese (Doutorado). Bauru: Universidade Estadual Paulista Júlio de Mesquita Filho - UNESP, Faculdade de Arquitetura, Artes e Comunicação, 2020. 
HALSE, J.; BRANDT, E.; CLARK, B.; BINDER, T. (Eds.). Rehearsing the future. Copenhagen: The Danish Design School Press, 2010.

MARTIM, Bella.; HANINGTON, Bruce.; Universal Design Methods: 100 ways to research complex problems, develop innovate ideas, asd design effective solutions. Rockport Publishers, 2012.

SANTOS, Camila Andrade. Design participativo nas margens: democracia e direito de brincar numa situação de quilombo urbano no Brasil, 2020. Projeto de tese (doutorado) - Faculdade de Arquitetura da Universidade de Lisboa, Lisboa, 2020.

SERPA, Bibiana; JULIANO, Clara; ANASTASSAKIS, Zoy; "Design Anthropology e Design Ativismo: investigando métodos situados", p. 1580-1596. In: Anais do $13^{\circ}$ Congresso Pesquisa e

Desenvolvimento em Design (2018). São Paulo: Blucher, 2019.

UNICEF, Convenção sobre o direito das crianças. Comitê Português para a UNICEF, 2019. BRIOZZO, Erica; GONZALES, Giovanna; GUILHERME, Janice; ARMA, Rosa. Vozes do Direita à cidade: fotografia participativa com as crianças do Bairro da Torre e do Alto da Cova da Moura, 2021. Projeto de pesquisa - Faculdade de Arquitetura da Universidade de Lisboa, Lisboa, 2021. 